\title{
Prevalence of Sarcopenia and Its Relationship with Nutritional State and Quality of Life in Patients with Digestive Diseases
}

\author{
Sachiyo ONISHI ${ }^{1}$, Makoto SHIRAKI ${ }^{1, *}$, Kayoko NishimURA ${ }^{2}$, Tatsunori HANAI ${ }^{1}$, \\ Hisataka MORIWAKI ${ }^{1}$ and Masahito SHIMIZU ${ }^{1}$ \\ ${ }^{1}$ Department of Gastroenterology/Internal Medicine, Gifu University Graduate School of Medicine, \\ 1-1 Yanagido, Gifu 501-1194, Japan \\ ${ }^{2}$ Nutrition Support Team/Infection Control Team, Gifu University Hospital, \\ 1-1 Yanagido, Gifu 501-1194, Japan
}

(Received June 14, 2018)

\begin{abstract}
Summary This study aimed to clarify the prevalence of sarcopenia, which is characterized by loss of skeletal muscle mass and strength, and its relationship with nutritional state and quality of life (QOL) in patients with digestive diseases. This study enrolled 303 patients (187 men and 116 women with a median age of $70 \mathrm{y}$ ) having digestive diseases. Diseases were gastrointestinal in 99 patients, biliary/pancreatic in 93, and hepatic in 111. Skeletal muscle cross-sectional area was measured by abdominal computed tomography at the 3rd vertebra (L3) level. Sarcopenia was defined using the L3 skeletal muscle index and hand grip strength. Nutritional state was assessed by Subjective Global Assessment (SGA), Mini nutritional Assessment ${ }^{\mathbb{}}$-Short Form (MNA ${ }^{\circledR}$-SF), anthropometry, and blood biochemistry. QOL was evaluated by Short Form- $8^{\mathrm{TM}}$. Prevalence of sarcopenia was $32.0 \%$ in overall cases. The value was $22.2 \%$ in gastrointestinal disease, $36.6 \%$ in biliary/pancreatic disease, and $36.9 \%$ in hepatic disease. Advanced age, male sex, and advanced cancer state were associated with development of sarcopenia. Patients with sarcopenia had a significantly worse nutritional state according to SGA and $\mathrm{MNA}^{\circledR}$-SF than those without sarcopenia. In anthropometry, \% arm muscle area, \% calf circumference, and body mass index were significantly lower in the sarcopenic group. Serum albumin and hemoglobin were also significantly lower in the sarcopenia patients. QOL was more impaired in physical component subscales in sarcopenia patients than non-sarcopenia ones. Patients with digestive diseases frequently suffer from sarcopenia and this is associated with worsening of nutritional state and QOL in these patients.
\end{abstract}

Key Words sarcopenia, digestive disease, quality of life, nutritional assessment

According to a 2010 statement by the European Working Group on Sarcopenia in Older People (EWGSOP), sarcopenia is a syndrome associated with risk for harmful outcomes such as decreased physical activity, decreased quality of life (QOL), and death (1). Sarcopenia is characterized by progressive and generalized loss of skeletal muscle mass and muscle strength (1), thus, leading to physical obstacles and health disturbances, including higher risk of mobility disturbance, falls and fractures, decreases in activities of daily living, physical disability, loss of autonomy, and increased risk of death (2-6).

Recently, the presence of both low muscle mass and low muscle function (strength and performance) have been used for the diagnosis of sarcopenia. Sarcopenia is found mainly in the elderly, but can also occur in young adults. Sarcopenia is classified as primary and secondary sarcopenia according to the cause (1). Secondary sarcopenia should be considered when one or more causes are evident, such as activity-related sarcopenia, disease-related sarcopenia, or nutrition-related sarcope-

*To whom correspondence should be addressed.

E-mail: gogo_nishi0924@yahoo.co.jp nia (1). Many factors have been reported in the development of sarcopenia, such as nervous system causes, hormonal changes, metabolic changes, nutritional state, immune state, and inflammatory reactions, all of which can be involved in loss of muscle mass and loss of muscle strength. In particular, complication with malignancy and chronic inflammatory disease are significantly involved in sarcopenia development $(7,8)$.

Previous studies have reported the prevalence of sarcopenia in patients with digestive diseases as, for example, $48 \%$ in pancreatic cancer (9), $38.9 \%$ in preoperative primary colorectal cancer, which is notably more common in those aged $>65 \mathrm{y}(10)$, and $40 \%$ in liver cirrhosis before liver transplantation (11). It is also reported that sarcopenia predicts the prognosis of patients having several types of digestive organ cancers $(12,13)$. Therefore, sarcopenia might be a critical target to improve the prognosis and QOL of cancer patients and, for this purpose, it is necessary to make a correct diagnosis of sarcopenia. However, most previous studies defined sarcopenia only by the loss of skeletal muscle mass, while muscle strength or physical performance was not evaluated. 
Patients with digestive diseases not only have a higher prevalence of malignant tumors, but may also experience impaired absorption and digestion $(1,4)$. Therefore, such patients are exposed to a higher risk for sarcopenia. However, no reports have described the prevalence of sarcopenia encompassing the entire spectrum of digestive diseases or in each disease entity. Furthermore, the relationship between sarcopenia and nutritional state or QOL is largely unknown in these patients. To address such concern, we conducted the present study to elucidate the prevalence of sarcopenia, which was diagnosed by assessing both volume of skeletal muscle mass and muscle strength, and to explore its possible relationship with nutritional state and QOL in patients with digestive diseases.

\section{MATERIALS AND METHODS}

Patients. We recruited 303 consecutive inpatients with digestive diseases at Gifu University Hospital from May 2013 to March 2014. All cases were first hospitalization to receive initial treatment. All patients underwent CT of the abdomen for diagnostic purposes. The study protocol was approved by the ethics committee of Gifu University School of Medicine (29-19 observation study on sarcopenia and quality of life), and carried out in accordance with the 1975 Helsinki Declaration as revised in 1983.

Nutritional assessment. We used the Subjective Global Assessment (SGA) (14) and Mini nutritional Assessment ${ }^{\circledR}$-Short Form $\left(\mathrm{MNA}^{\circledR}\right.$-SF) (15) for nutritional assessment. To avoid possible variance among observers, the SGA and MNA ${ }^{\circledR}$-SF were administered by a certified dietitian within $3 \mathrm{~d}$ of hospital admission. Anthropometric data were collected at the same time. According to the SGA, we defined group A as patients who were determined to have good nutritional state, group $\mathrm{B}$ as patients with moderate malnutrition, and group $\mathrm{C}$ as patients with advanced malnutrition. Using the MNA ${ }^{\circledR}$-SF, we defined $12-14$ points out of a maximum total of 14 points as well nourished, 8-11 points as at risk of malnutrition, and 0-7 points as malnourished.

Anthropometry. On admission, the patients' height and weight were measured, and their body mass index (BMI) was calculated. Arm circumference (AC), triceps skinfold thickness (TSF), and calf circumference (CC) were measured using Insertape and the Adipometer (Abbott Japan Co., Ltd., Tokyo, Japan). The arm muscle area (AMA) was calculated as follows: AMA $\left(\mathrm{cm}^{2}\right)=\{$ AC $(\mathrm{cm})-0.314 \times \mathrm{TSF}(\mathrm{cm})\}^{2} / 4$.

According to the anthropometric reference values for the Japanese population published by the Japanese Nutrition Assessment Study Group (Japanese Anthropometric Reference Data, JARD 2001) (16), we calculated \%TSF, \%AMA, and \%CC by taking the median JARD value of each age as $100 \%$.

Laboratory data. Serum albumin, hemoglobin, and C-reactive protein (CRP) were measured on admission with a standard clinical analyzer at the central laboratory of Gifu University Hospital. The results of the blood test obtained on the first hospital day were used for analysis.

Diagnosis of sarcopenia. Skeletal muscle cross-sectional area was quantified using a single-slice computed tomography (CT) scan at the 3rd vertebra (L3) level, which is strongly correlateed with whole body muscle mass (17). L3 skeletal muscle area was analyzed by sliceOmatic software version 5.0 (TomoVision, Montreal, QC), which enables specific tissue demarcation using the Hounsfield unit (HU) from -29 to +150 (17-19). To standardize the area according to patients' stature, L3 skeletal muscle area at L3 $\left(\mathrm{cm}^{2}\right)$ was divided by height squared $\left(\mathrm{m}^{2}\right)$, giving the skeletal muscle index (SMI) $\left(\mathrm{cm}^{2} / \mathrm{m}^{2}\right)(20)$. We defined loss of muscle mass based on an SMI cut-off of $<52.4 \mathrm{~cm}^{2} / \mathrm{m}^{2}$ for males and $<38.5 \mathrm{~cm}^{2} / \mathrm{m}^{2}$ for females (21).

The grip strength was measured in both arms and the average was determined. We defined loss of muscle strength based on a cut-off of $<30 \mathrm{~kg}$ for males and $<20 \mathrm{~kg}$ for females $(1,3)$. We diagnosed patients as having sarcopenia when they fulfilled both the criteria for SMI and those for grip strength.

QOL assessment. Health-related QOL was measured using the Short Form- $8^{\mathrm{TM}}\left(\mathrm{SF}-8^{\mathrm{TM}}\right)$ health survey questionnaire authorized by NPO Health Care Evaluation and Research Institute iHope (http://www.i-hope.jp/). Measures of health-related quality of life (HRQOL) are classified into comprehensive scales and disease-specific scales, and SF- $8^{\mathrm{TM}}$ belongs to the former. Thus, the form allows measurement of HRQOL in patients having any disease and enables comparisons among different diseases. The SF- $8^{\mathrm{TM}}$ contains 8 questions that provide a quantitative evaluation for each of eight subscales: physical functioning (PF), role physical (RP), bodily pain (BP), general health perception (GH), vitality (VT), social functioning (SF), role emotional (RE), and mental health $(\mathrm{MH})$. In addition, summary scores are available for physical component (PCS) from PF and RP, and for mental component (MCS) from RE and MH.

Statistical analysis. Statistical analysis was performed using JMP version 9.0.2 software (SAS Institute, Cararey, NC). Continuous variables are expressed as median (range), and differences between median values were nonparametrically analyzed using the Mann-Whitney $U$ test. Categorical variables are given as number of patients, and differences in their distribution between groups were tested by the chi-squared test. Statistical significance was declared with $p<0.05$.

\section{RESULTS}

\section{Patient characteristics}

The patients' baseline clinical characteristics are shown in Table 1. A total of 303 patients was enrolled in this study. The patients consisted of 187 men (61.7\%) and 116 women (38.3\%) with a median age of $70 \mathrm{y}$ (range, 22-98). There was no significant difference in gender or age among the disease categories.

Patients with gastrointestinal diseases $(n=99)$ included gastrointestinal intramucosal cancer (nonadvanced cancer; $n=58$ ), advanced gastrointestinal cancer $(n=11)$, gastrointestinal bleeding (gastric ulcer, 
Table 1. Patient characteristics in each disease group.

\begin{tabular}{|c|c|c|c|c|c|}
\hline & Total & $\begin{array}{c}\text { Gastrointestinal } \\
\text { disease }\end{array}$ & $\begin{array}{c}\text { Biliary pancreatic } \\
\text { disease }\end{array}$ & $\begin{array}{l}\text { Hepatic } \\
\text { disease }\end{array}$ & $p$ value \\
\hline Number & 303 & 99 & 93 & 111 & \\
\hline \multicolumn{6}{|l|}{ Gender } \\
\hline Male & 187 & 63 & 58 & 66 & \multirow{2}{*}{0.81} \\
\hline Female & 116 & 36 & 35 & 45 & \\
\hline Age (y) & $70(22-98)$ & $69(24-85)$ & $69(32-98)$ & $73(22-89)$ & 0.08 \\
\hline \multicolumn{6}{|c|}{ Advanced cancer } \\
\hline Present & 128 & 11 & 53 & 64 & \multirow{2}{*}{$<0.01$} \\
\hline Absent & 175 & 88 & 40 & 47 & \\
\hline Alb & $3.8(2-4.9)$ & $4.1(2.2-4.8)$ & $3.8(2.0-4.8)$ & $3.5(2.3-4.9)$ & $<0.01$ \\
\hline AST & $35(8-12,315)$ & $21(8-141)$ & $47(9-2,087)$ & $49(13-12,315)$ & 0.18 \\
\hline ALT & $27(5-4,457)$ & $17(5-845)$ & $47(5-1,632)$ & $34(8-4,457)$ & 0.04 \\
\hline T-Bil & $0.9(0.3-28)$ & $0.6(0.3-4.6)$ & $1.3(0.4-23.8)$ & $1.0(0.4-28)$ & $<0.01$ \\
\hline $\mathrm{Hb}$ & $12.8(3.8-17.5)$ & $13.2(3.8-16.6)$ & $12.5(7.6-16.9)$ & $12.8(4.8-17.5)$ & 0.99 \\
\hline CRP & $0.21(0.02-35.77)$ & $0.1(0.02-35.77)$ & $0.62(0.02-26.19)$ & $0.465(0.02-13.84)$ & 0.01 \\
\hline T-chol & $169(49-1,223)$ & $179(49-298)$ & $187(80-1,223)$ & $154(87-270)$ & 0.01 \\
\hline Lymph & $1,369(186-5,370)$ & $1,522(387-5,370)$ & $1,209(3,487-2,390)$ & $1,131(186-3,690)$ & $<0.01$ \\
\hline
\end{tabular}

Alb: albumin(g/dL), AST: asparate amino transferase (U/L), ALT: alanine amino transferase (U/L), T-Bil: total bilirubin (mg/ $\mathrm{dL}), \mathrm{Hb}$ : hemoglobin $(\mathrm{g} / \mathrm{dL}), \mathrm{CRP}$ : C-reactive protein $(\mathrm{mg} / \mathrm{dL})$, T-chol: total cholesterol (mg/dL), Lymph: lymphcyte count $(/ \mu \mathrm{L})$.

Values indicate number of patients or median (range).

Statistical analysis was performed by chi-squared test or Mann-Whitney $U$ test.

Table 2. Muscle mass and muscle strength in patients with digestive diseases.

\begin{tabular}{|c|c|c|c|c|}
\hline & & \multicolumn{2}{|c|}{ Muscle strength } & \multirow{2}{*}{ Subtotal } \\
\hline & & Low & Normal & \\
\hline \multirow[t]{2}{*}{ Muscle mass } & Low & $97(32.0 \%)$ & $112(37.0 \%)$ & $209(69.0 \%)$ \\
\hline & Normal & $46(15.2 \%)$ & $48(15.8 \%)$ & $94(31.0 \%)$ \\
\hline Subtotal & & $143(47.2 \%)$ & $160(52.8 \%)$ & $303(100 \%)$ \\
\hline \multirow[t]{2}{*}{ SMI } & Low & 97 & 112 & $209(69.0 \%)$ \\
\hline & Normal & 46 & $48(15.85 \%)$ & 94 \\
\hline Subtotal & & $143(47.2 \%)$ & 160 & 303 \\
\hline
\end{tabular}

Values are number of patients (percentages).

duodenal ulcer, and diverticular bleeding; $n=16$ ), inflammatory bowel disease $(n=10)$, and other diseases $(n=4)$. Biliary/pancreatic diseases $(n=93)$ included pancreatic cancer $(n=37)$, cholangiocarcinoma $(n=13)$, cholangitis $(n=10)$, common bile duct stones $(n=11)$, pancreatitis $(n=5)$, cholecystitis $(n=4)$, gallbladder cancer $(n=3)$, intraductal papillary mucinous neoplasm $(n=3)$, pancreatic pseudocyst $(n=2)$, and other diseases $(n=5)$. Hepatic diseases $(n=111)$ included hepatocellular carcinoma $(n=64)$, liver cirrhosis $(n=23)$, chronic hepatitis $(n=12)$, acute hepatitis (alcoholic or hepatitis B virus; $n=11)$, and liver failure $(n=1)$.

There were significant diffrences in the cancer-carrying rate $(p<0.01)$, serum albumin levels $(p<0.01)$, serum alanine amino transferase levels $(p=0.04)$, total bilirubin levels $(p<0.01)$, C-reactive protein (CRP) lev- els $(p=0.01)$, total cholesterol levels $(p=0.01)$, and the number of lymphocytes $(p<0.01)$ among the groups.

\section{Prevalence of sarcopenia}

Among the enrolled patients, 32.0\% (97/303) were diagnosed with sarcopenia. Low muscle mass was observed in $69.0 \%$ of total patients $(209 / 303)$, while loss of muscle strength was in 47.2\% (143/303). Only $15.8 \%$ (48/303) were normal in both muscle mass and muscle strength (Table 2). The prevalence of sarcopenia was $22.2 \%(22 / 99)$ in gastrointestinal disease, $36.6 \%$ (34/93) in biliary/pancreatic disease, and 36.9\% $(41 / 111)$ in hepatic disease. The prevalence was significantly lower in gastrointestinal disease than in the other two groups $(p<0.05)$ (Fig. 1). Relationships between sarcopenia and patients' baseline characteristics are shown in Table 3. In overall patients with digestive dis- 


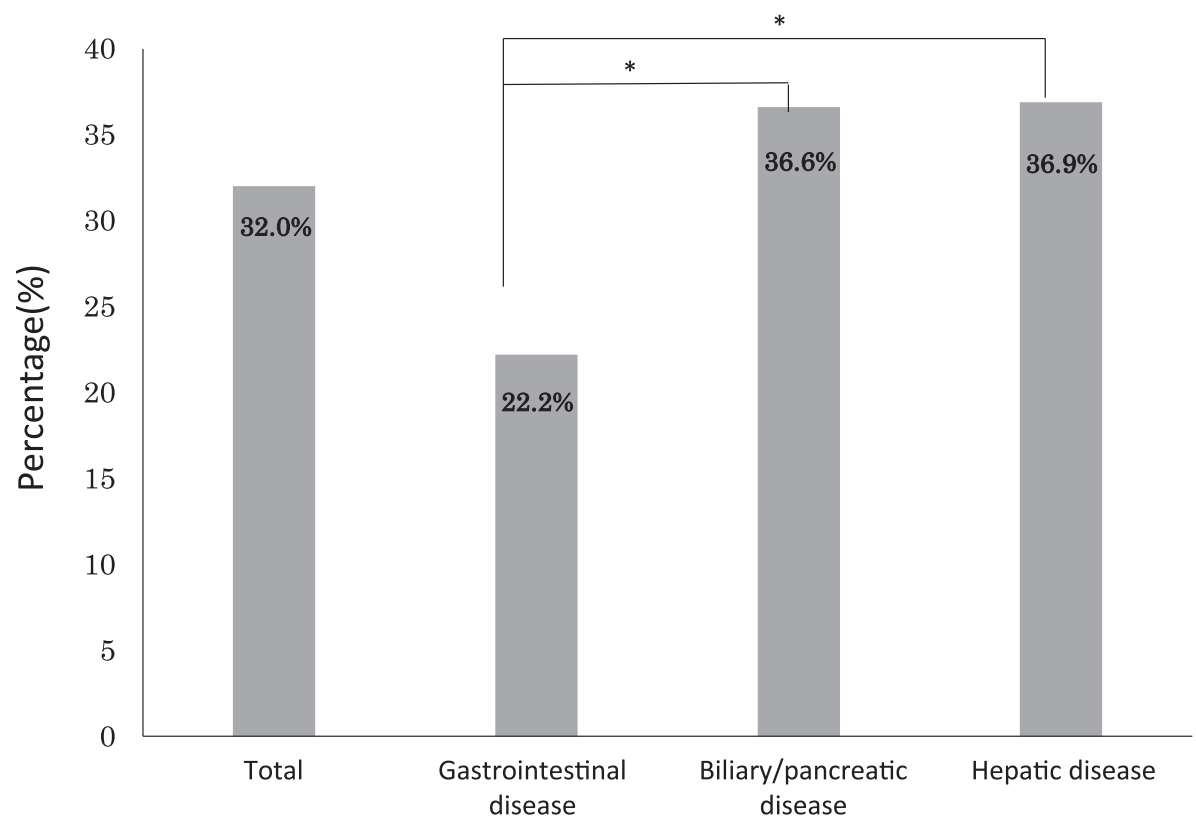

Fig. 1. Prevalence of sarcopenia in patients with digestive diseases. ${ }^{*} p<0.05$ by Mann-Whitney $U$ test.

Table 3. Sarcopenia and patients' baseline characteristics.

\begin{tabular}{|c|c|c|c|c|c|c|}
\hline & & & Sarcopenia & Non-sarcopenia & Total & $p$ value \\
\hline \multirow{5}{*}{$\begin{array}{l}\text { Gastrointestinal } \\
\text { disease }\end{array}$} & Gender & Male & 16 & 47 & 63 & \multirow{2}{*}{0.31} \\
\hline & & Female & 6 & 30 & 36 & \\
\hline & Age (y) & & $73(47-85)$ & $67(24-84)$ & $69(24-85)$ & $<0.01$ \\
\hline & \multirow{2}{*}{$\begin{array}{l}\text { Advanced } \\
\text { cancer }\end{array}$} & Present & 5 & 6 & 11 & \multirow{2}{*}{0.04} \\
\hline & & Absent & 17 & 71 & 88 & \\
\hline \multirow{5}{*}{$\begin{array}{l}\text { Biliary/pancreatic } \\
\text { disease }\end{array}$} & \multirow[t]{2}{*}{ Gender } & Male & 22 & 36 & 58 & \multirow{2}{*}{0.81} \\
\hline & & Female & 12 & 23 & 35 & \\
\hline & \multicolumn{2}{|l|}{ Age (y) } & $73(55-98)$ & $68(32-84)$ & $69(32-98)$ & 0.02 \\
\hline & Advanced & Present & 19 & 34 & 53 & \multirow{2}{*}{1.00} \\
\hline & cancer & Absent & 15 & 25 & 40 & \\
\hline \multirow{5}{*}{$\begin{array}{l}\text { Hepatic } \\
\text { disease }\end{array}$} & \multirow[t]{2}{*}{ Gender } & Male & 30 & 36 & 66 & \multirow{2}{*}{0.02} \\
\hline & & Female & 11 & 34 & 45 & \\
\hline & \multicolumn{2}{|l|}{ Age (y) } & $76(45-89)$ & $69(22-87)$ & $73(22-89)$ & $<0.01$ \\
\hline & \multirow{2}{*}{$\begin{array}{l}\text { Advanced } \\
\text { cancer }\end{array}$} & Present & 25 & 39 & 64 & \multirow{2}{*}{0.59} \\
\hline & & Absent & 16 & 31 & 47 & \\
\hline \multirow[t]{5}{*}{ Total } & \multirow[t]{2}{*}{ Gender } & Male & 68 & 119 & 187 & \multirow{2}{*}{0.04} \\
\hline & & Female & 29 & 87 & 116 & \\
\hline & Age (y) & & $75(45-98)$ & $69(22-87)$ & $70(22-98)$ & $<0.01$ \\
\hline & \multirow{2}{*}{$\begin{array}{c}\text { Advanced } \\
\text { cancer }\end{array}$} & Present & 49 & 79 & 128 & \multirow{2}{*}{0.04} \\
\hline & & Absent & 48 & 127 & 175 & \\
\hline
\end{tabular}

Values are number of patients or median (range).

Statistical analysis was performed by chi-squared test or Mann-Whitney $U$ test. 
Table 4. The relationship between sarcopenia and nutritional state assessed by Subjective Global Assessment (SGA) and Mini nutritional Assessment ${ }^{\mathbb{}}$-Short Form $\left(\mathrm{MNA}^{\circledR}-\mathrm{SF}\right)$.

\begin{tabular}{|c|c|c|c|c|c|c|}
\hline & & & Sarcopenia & Non-sarcopenia & Total & $p$ value \\
\hline \multirow{6}{*}{$\begin{array}{l}\text { Gastrointestinal } \\
\text { disease }\end{array}$} & SGA & A & 17 & 63 & 80 & \\
\hline & & B & 3 & 9 & 12 & 0.95 \\
\hline & & $\mathrm{C}$ & 1 & 3 & 4 & \\
\hline & $\mathrm{MNA}^{\circledR}-\mathrm{SF}$ & Well nourished & 8 & 43 & 51 & \\
\hline & & At risk & 11 & 28 & 39 & 0.32 \\
\hline & & Malnourished & 2 & 5 & 7 & \\
\hline \multirow{6}{*}{$\begin{array}{l}\text { Biliary/pancreatic } \\
\text { disease }\end{array}$} & SGA & A & 15 & 47 & 62 & \\
\hline & & B & 9 & 10 & 19 & $<0.01$ \\
\hline & & $\mathrm{C}$ & 8 & 2 & 10 & \\
\hline & $\mathrm{MNA}^{\circledR}-\mathrm{SF}$ & Well nourished & 8 & 22 & 30 & \\
\hline & & At risk & 12 & 28 & 40 & 0.03 \\
\hline & & Malnourished & 13 & 9 & 22 & \\
\hline \multirow{6}{*}{$\begin{array}{l}\text { Hepatic } \\
\text { disease }\end{array}$} & SGA & A & 20 & 53 & 73 & \\
\hline & & B & 16 & 12 & 28 & 0.01 \\
\hline & & $\mathrm{C}$ & 5 & 4 & 9 & \\
\hline & $\mathrm{MNA}^{\circledR}$-SF & Well nourished & 18 & 40 & 58 & \\
\hline & & At risk & 12 & 27 & 39 & $<0.01$ \\
\hline & & Malnourished & 10 & 3 & 13 & \\
\hline \multirow[t]{6}{*}{ Total } & SGA & A & 52 & 163 & 215 & \\
\hline & & B & 28 & 31 & 59 & $<0.01$ \\
\hline & & $\mathrm{C}$ & 14 & 9 & 23 & \\
\hline & $\mathrm{MNA}^{\circledR}-\mathrm{SF}$ & Well nourished & 34 & 105 & 139 & \\
\hline & & At risk & 35 & 83 & 118 & $<0.01$ \\
\hline & & Malnourished & 25 & 17 & 42 & \\
\hline
\end{tabular}

Values are number of patients.

Statistical analysis was performed by chi-squared test.

eases, sarcopenia patients were significantly older than those without sarcopenia. Sarcopenia was also more prevalent in males and in patients with malignancy. Presence of malignancy and age are significantly associated with sarcopenia in patients with gastrointestinal diseases. Male sex and age are also involved in sarcopenia with hepatic disease patients. In patients with biliary/pancreatic diseases, only older age is associated with sarcopenia. Significant difference in patients' age was similarly observed in 3 disease entities. The length of hospital stay did not differ between sarcopenic and non-sarcopenic patients (data not shown).

Relationship between sarcopenia and nutritional state

The scores for Subjective Global Assessment (SGA) and Mini nutritional Assessment ${ }^{\circledR}$-Short Form (MNA ${ }^{\circledR}$-SF) were assessed in 297 and 299 of the enrolled patients, respectively. Sarcopenia patients had significantly higher incidence of malnutrition as assessed by both SGA and $\mathrm{MNA}^{\circledR}$-SF overall as well as in biliary/pancreatic and hepatic disease, but not in gastrointestinal disease (Table 4).
Relationship between sarcopenia and anthropometry

As shown in Table 5, body mass index (BMI), \% arm muscle area (\%AMA), and \% calf circumference (\%CC) were significantly lower in sarcopenia patients than in non-sarcopenia ones overall, and in the patients enrolled with biliary/pancreatic and hepatic diseases. Difference in \% triceps skinfold thickness (\%TSF) was also significant only in patients with biliary/pancreatic diseases. On the other hand, no significant difference was seen in any anthropometry in gastrointestinal disease.

Relationship between sarcopenia and laboratory data

As shown in Table 6, significant differences were observed in serum albumin and hemoglobin between sarcopenia patients and non-sarcopenia patients with overall digestive diseases or with biliary/pancreatic diseases. CRP was not significantly different between sarcopenia and non-sarcopenia in any disease category.

Relationship between sarcopenia and $Q O L$

QOL scores of the patients with digestive diseases were below the national standard value in all subscales (Fig. 2). The sarcopenia group showed significantly lower scores in four of eight subscales, including physi- 
Table 5. The relationship between sarcopenia and anthropometry.

\begin{tabular}{|c|c|c|c|c|c|}
\hline & & Sarcopenia & Non-sarcopenia & Total & $p$ value \\
\hline \multirow{4}{*}{$\begin{array}{l}\text { Gastrointestinal } \\
\text { disease }\end{array}$} & BMI & $19.6(16.5-27.9)$ & $21.3(13.9-31.7)$ & $21.3(13.9-31.7)$ & 0.73 \\
\hline & $\% \mathrm{TSF}$ & $100(43-260)$ & $100(40-300)$ & $100(40-300)$ & 0.97 \\
\hline & \%AMA & $87.3(47.4-142.0)$ & $90.8(27.3-142.9)$ & $90.1(27.3-142.9)$ & 0.62 \\
\hline & $\% \mathrm{CC}$ & $98.0(81.9-123.0)$ & $97.1(78.1-123.0)$ & $97.8(78.1-123.0)$ & 0.93 \\
\hline \multirow{4}{*}{$\begin{array}{l}\text { Biliary/pancreatic } \\
\text { disease }\end{array}$} & BMI & $20.2(15.6-31.6)$ & $21.8(16.3-27.4)$ & $21.5(15.6-31.6)$ & 0.04 \\
\hline & $\% \mathrm{TSF}$ & $88(50-240)$ & $115(40-244)$ & $106(40-244)$ & 0.04 \\
\hline & \%AMA & $73.9(47.3-108.0)$ & $85.4(44.4-127.0)$ & $81.9(44.4-127.0)$ & $<0.01$ \\
\hline & $\% \mathrm{CC}$ & $93.8(75.2-117.0)$ & $97.2(71.4-125.3)$ & $96.7(71.4-125.3)$ & 0.02 \\
\hline \multirow{4}{*}{$\begin{array}{l}\text { Hepatic } \\
\text { disease }\end{array}$} & BMI & $21.7(16.8-30.7)$ & $22.9(18.6-32.0)$ & $22.4(16.8-32.0)$ & 0.01 \\
\hline & $\% \mathrm{TSF}$ & $100(22-216)$ & $108(22-333)$ & $100(22-333)$ & 0.71 \\
\hline & \%AMA & $105.7(50.7-188.5)$ & $131.9(39.8-279.5)$ & $121.9(39.8-279.5)$ & 0.01 \\
\hline & $\% \mathrm{CC}$ & $95.1(72.9-112.3)$ & $101.4(82.3-128)$ & $99.4(72.9-128.0)$ & $<0.01$ \\
\hline \multirow[t]{4}{*}{ Total } & BMI & $21.1(15.6-31.6)$ & $22.1(13.9-32.0)$ & $21.8(13.9-32.0)$ & 0.01 \\
\hline & $\% \mathrm{TSF}$ & $100(22-260)$ & $110(22-333)$ & $100(22-333)$ & 0.22 \\
\hline & $\%$ AMA & $90.9(47.3-188.5)$ & $95.9(27.3-279.5)$ & $93.9(27.3-279.5)$ & 0.03 \\
\hline & $\% \mathrm{CC}$ & $95.1(72.9-123.0)$ & $98.2(71.4-128.0)$ & $97.7(71.4-128.0)$ & $<0.01$ \\
\hline
\end{tabular}

BMI: body mass index, \%TSF: \% triceps skinfold thickness, \%AMA: \% arm muscle area, \%CC: \% calf circumference. Values are expressed as median (range).

Statistical analysis was performed by Mann-Whitney $U$ test.

Table 6. The relationship between sarcopenia and laboratory data.

\begin{tabular}{|c|c|c|c|c|c|}
\hline & & Sarcopenia & Non-sarcopenia & Total & $p$ value \\
\hline \multirow{3}{*}{$\begin{array}{l}\text { Gastrointestinal } \\
\text { disease }\end{array}$} & Alb & $4.0(2.7-5.2)$ & $4.1(2.2-4.8)$ & $4.0(2.2-5.2)$ & 0.76 \\
\hline & $\mathrm{Hb}$ & $10.9(8.9-16.6)$ & $13.0(3.8-15.7)$ & $12.9(3.8-16.6)$ & 0.86 \\
\hline & CRP & $0.07(0.02-27.7)$ & $0.11(0.02-35.8)$ & $0.1(0.02-35.8)$ & 0.17 \\
\hline \multirow{3}{*}{$\begin{array}{l}\text { Biliary/pancreatic } \\
\text { disease }\end{array}$} & Alb & $3.4(2.0-4.5)$ & $3.9(2.2-4.8)$ & $3.8(2.0-4.8)$ & $<0.01$ \\
\hline & $\mathrm{Hb}$ & $11.3(7.6-15.6)$ & $12.9(8.4-16.2)$ & $12.3(7.6-16.2)$ & $<0.01$ \\
\hline & CRP & $1.28(0.02-32.1)$ & $0.37(0.02-21.3)$ & $0.65(0.02-32.1)$ & 0.09 \\
\hline \multirow{3}{*}{$\begin{array}{l}\text { Hepatic } \\
\text { disease }\end{array}$} & Alb & $3.4(2.0-4.4)$ & $3.7(2.0-4.9)$ & $3.6(2.0-4.9)$ & 0.07 \\
\hline & $\mathrm{Hb}$ & $11.8(7.2-15.4)$ & $12.5(7.1-17.5)$ & $12.2(7.1-17.5)$ & 0.16 \\
\hline & CRP & $0.28(0.02-7.89)$ & $0.2(0.02-34.5)$ & $0.25(0.02-34.5)$ & 0.49 \\
\hline \multirow[t]{3}{*}{ Total } & Alb & $3.6(2.0-5.2)$ & $3.9(2.0-4.9)$ & $3.8(2.0-5.2)$ & $<0.01$ \\
\hline & $\mathrm{Hb}$ & $11.7(7.2-16.6)$ & $12.7(3.8-17.5)$ & $12.3(3.8-17.5)$ & 0.01 \\
\hline & CRP & $0.39(0.02-32.1)$ & $0.19(0.02-35.8)$ & $0.23(0.02-35.8)$ & 0.09 \\
\hline
\end{tabular}

Alb: albumin (g/dL), Hb: hemoglobin (g/dL), CRP: C-reactive protein (mg/dL).

Values are expressed as median (range).

Statistical analysis was performed by Mann-Whitney $U$ test.

cal functioning $(\mathrm{PF})$, role physical (RP), general health perception $(\mathrm{GH})$, and role emotional $(\mathrm{RE})$. regarding the summary scores, physical component (PCS) was significantly lower in sarcopenia patients than in non-sarcopenia ones.

\section{DISCUSSION}

This is the first study to assess sarcopenia by both quantity and strength of skeletal muscle and to report a significant correlation of sarcopenia with nutritional state and QOL in digestive diseases. The results of the present study clearly showed that sarcopenia patients had a worse nutritional state and deeper deterioration of QOL than non-sarcopenia patients. In this study, the prevalence of sarcopenia was $32.0 \%$ in patients with digestive diseases. In particular, the prevalence was significantly high when the patients had biliary/pancreatic disease $(36.6 \%)$ and hepatic disease $(36.9 \%)$. These rates were higher than $20 \%$ in the general population of elderly Japanese aged over 65 y (22). In diges- 


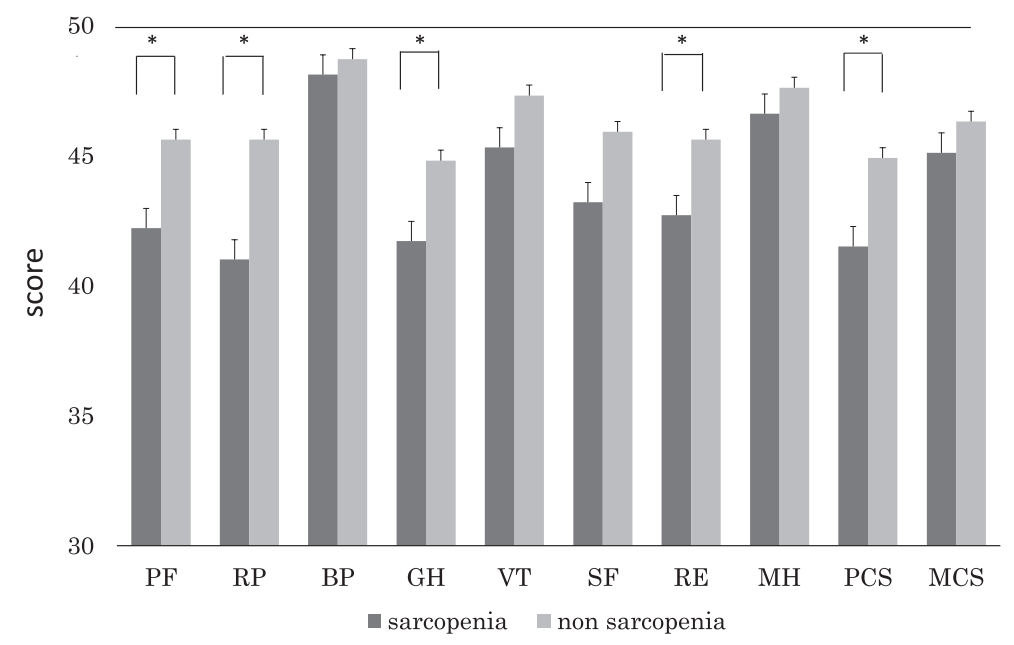

Fig. 2. Relationship between sarcopenia and quality of life. Quality of life (QOL) was measured using the Short Form$8^{\mathrm{TM}}\left(\mathrm{SF}-8^{\mathrm{TM}}\right)$. Horizontal line at score 50 indicates the national standard value (https://www.sf-36.jp/qol/sf8.html). PF: physical functioning, RP: role physical, BP: bodily pain, GH: general health, VT: vitality, SF: social functioning, RE: role emotional, MH: mental health, PCS: physical component summary calculated as a mean of PF and RP, MCS: mental component summary as a mean of RE and MH. ${ }^{*} p<0.05$ by Mann-Whitney $U$ test.

tive diseases, sarcopenia could become highly prevalent through nutritional disorder due to reduced dietary intake and digestion or absorption abnormality.

In the present study, we evaluated the study patients' nutritional state with two assessment tools, SGA and $\mathrm{MNA}^{\circledR}$-SF, both of which are widely used for nutritional investigation without requiring blood examination. The patients with sarcopenia were revealed to have a significantly worse nutritional state by both SGA and MNA ${ }^{\circledR}$-SF than those without sarcopenia, which indicated that these tools for nutritional investigation might be useful to screen sarcopenic patients with worse prognosis. A similar result was also obtained from the evaluation of CONUT (Controlling Nutrition Status) score, which was determined by clinical biochemistry and hematology parameters, because the median CONUT score was 4 for patients with sarcopenia and 2 for patients without sarcopenia (data not shown).

A previous study reported that SGA is useful to predict hospital stay in digestive disease patients (23), but we identified only the $\mathrm{MNA}^{\circledR}$-SF score as correlating with muscle strength as well as muscle mass (data not shown). Therefore, MNA ${ }^{\circledR}$-SF might be better associated with sarcopenia in digestive diseases. We also assessed the nutritional state of patients by anthropometry and laboratory data. In anthropometry, we found that BMI, \%AMA, and \%CC, all of which are associated with protein and energy nutrition, were significantly lower in sarcopenia patients than in non-sarcopenia patients. Serum albumin was also similarly lower in sarcopenia. However, it is generally accepted that nutritional assessment using only BMI, \%AMA, and \%CC would be difficult due to the influence of fluid retention. Moreover, inflammation promotes protein consumption. Hence, we should be careful particularly in the evaluation of protein malnutrition in inflammatory digestive diseases.

Patients with digestive diseases claimed significantly lower QOL, especially physical QOL, in the sarcopenia group. Interestingly, it has been reported that patients with sarcopenia experience not only muscle weakness but also a higher prevalence of depressive symptoms (24), suggesting that sarcopenia has an influence on emotional state. For the prevention of deterioration of QOL, it might also be necessary to support psychologically the sarcopenia patients with digestive diseases. In addition, early detection and intervention of malnourished sarcopenia patients with a lower physical QOL will be required to, at least, maintain their QOL in the early stage of impairment. Sarcopenia, especially skeletal muscle depletion, has been reported to affect not only patients' QOL, but also their prognosis $(25,26)$. Recently the rate of skeletal muscle wasting has been found to preduct mortality (27).

Since muscle protein is maintained by a balance of anabolism and catabolism, promotion of anabolism and suppression of catabolism are effective for sarcopenia treatment. Lack of nutritional intake, vitamin D, or essential amino acids has been pointed out as responsible for the development of sarcopenia. Essential amino acids, especially leucine, stimulate protein synthesis by activating protein translation initiation factor and the mammalian target of the rapamycin signaling pathway in skeletal muscle (28). Actually, we have reported that branched chain amino acid (BCAA) supplementation significantly improved protein nutrition and, subsequently, prognosis for sarcopenia patients with liver cirrhosis (29). BCAA supplementation is reported to improve low muscle strength in patients with chronic liver disease (30). Sarcopenia and decreased serum BCAA levels were predictors of minimal hepatic encephalopathy, which spoils QOL (31). In addition, exercise also seems useful for treating sarcopenia in combination with BCAA. Recently, this combination was found to be effective not only for recovering muscle mass but also for 
improving muscle strength and physical performance in primary sarcopenia patients (32). Questions for future research include whether such treatment could prevent the onset of sarcopenia, especially in patients having chronic liver disease.

In comparison to gastrointestinal disease, biliary/ pancreatic disease and hepatic disease were more significantly associated with worse nutrition and anthropometry data in sarcopenic patients in the present study. We presume this is based on the patients' characteristics because more advanced cancer patients were enrolled in the biliary/pancreatic disease $(53 / 93,56.9 \%)$ and hepatic disease $(64 / 111,57.7 \%)$ groups compared to the gastrointestinal group $(11 / 99,11.1 \%)$. These findings are consistent with previous studies (33) and, therefore, it is necessary to pursue the effective countermeasure for sarcopenia in patients with malignancy.

The present study has several limitations. The first is insufficient availability of reference values to define sarcopenia. To standardize variations in ethnicity, body size, and cultural background, the Asian Working Group for Sarcopenia (AWGS) in 2013 proposed cut-off values for muscle mass by dual-energy X-ray absorptiometry (DEXA) or bioelectric impedance analysis (BIA) $\left(7.0 \mathrm{~kg} / \mathrm{m}^{2}\right.$ for men and $5.7 \mathrm{~kg} / \mathrm{m}^{2}$ for women), hand grip strength $(<26 \mathrm{~kg}$ for men and $<18 \mathrm{~kg}$ for women), and usual gait speed $(<0.8 \mathrm{~m} / \mathrm{s})$ (34). The AWGS recommended calculating the height-adjusted skeletal muscle mass using DEXA or BIA. On the other hand, skeletal muscle mass has been recommended by EWGSOP to be measured by computed tomography (CT) scan, magnetic resonance imaging, DEXA, and BIA (1). In the present study, because patients had undergone abdominal CT before admission for diagnostic purposes, we used CT scans to measure the 3rd vertebra (L3)skeletal muscle index (L3-SMI). Since information on L3-SMI in the Japanese population is limited, we relied on non-Japanese cut-off values $(20,21)$. Even though SMI is stature-adjusted, such application should be further validated in the future specifically for the Japanese population. In 2015, the Japan Society of Hepatology (JSH) decided to establish its own assessment criteria for sarcopenia in liver disease (35). The cut-off value for grip strength in the JSH criterion is based on AWGS and, therefore, further validation should be conducted using these Asian criteria.

The second limitation is that the pathological condition of enrolled patients was different. Several patients with conditions such as gastrointestinal bleeding, cholangitis/cholecystitis, and pancreatitis, were admitted to the hospital for an emergency. The nutrition status and/ or sarcopenia complication of these patients might be different from those of cancer-carrying patients, especially those who undergo surgery and/or chemotheraphy. On the other hand, we presume that the results of this study reflect the current status of the digestive disease ward in Japan.

In conclusion, the present study showed that $32 \%$ of patients with digestive diseases had sarcopenia. Such patients were worse nourished and had a lower QOL than those without sarcopenia. Possible interventions for sarcopenia need to be investigated in future studies.

\section{Supporting Information}

Supplemental Online Material is available on J-STAGE.

\section{REFERENCES}

1) Cruz-Jentoft AJ, Baeyens JP, Bauer JM, Boirie Y, Cederholm T, Landi F, Martin FC, Michel JP, Rolland Y, Schneider SM, Topinková E, Vandewoude M, Zamboni M; European Working Group on Sarcopenia in Older People. 2010. Sarcopenia; European consensus on definition and diagnosis; Report of the European Working Group on Sarcopenia in Older People. Age Ageing 39: 412-423.

2) Cawthon PM, Mershall LM, Michael Y, Dam TT, Ensrud KE, Barrett-Connor E, Orwoll ES, Osteoporotic Fractures in Men Research Group. 2007. Frailty in older men: prevalence, progression, and relationship with mortality. J Am Geriatr Soc 55: 1216-1223.

3) Laurentani F, Russo C, Bandinelli S, Bartali B, Cavazzini C, Di Iorio A, Corsi AM, Rantanen T, Guralnik JM, Ferrucci L. 2003. Age-associated changes in skeletal muscles and their effect on mobility: an operational diagnosis of sarcopenia. J Appl Physiol 95: 1851-1860.

4) Rolland Y, Czerwinski S, Abellan Van Kan G, Morley JE, Cesari M, Onder G, Woo J, Baumgartner R, Pillard F, Boirie Y, Chumlea WM, Vellas B. 2008. Sarcopenia: its assessment, etiology, pathogenesis, consequences and future perspectives. J Nutr Health Aging 12: 433-450.

5) Topinkova E. 2008. Aging, disability and frailty. Ann Nutr Metab 52: 6-11.

6) Hartman MJ, Fields DA, Byrne NM, Hunter GR. 2007. Resistance training improves metabolic economy during functional tasks in older adults. J Strength Cond Res 21 : 91-95.

7) Marcell TJ. 2003. Sarcopenia: causes, consequences and preventions. J Gerontol A Biol Sci Med Sci 58: 911-916.

8) Imai K, Takai K, Watanabe S, Hanai T, Suetsugu A, Shiraki M, Shimizu M. 2017. Sarcopenia impairs prognosis of patients with hepatocellular carcinoma: the role of liver functional reserve and tumor-related factors in loss of skeletal muscle volume. Nutrients 9: E1054.

9) Tan BH, Birdsell LA, Martin L, Baracos VE, Fearon KC. 2009. Sarcopenia in an overweight or obese patient is an adverse prognostic factor in pancreatic cancer. Clin Cancer Res 15: 6973-6979.

10) Lieffers JR, Bathe OF, Fassbender K, Winget M, Baracos VE. 2012. Sarcopenia is associated with postoperative infection and delayed recovery from colorectal cancer resection surgery. Br J Cancer 107: 931-936.

11) Montano-Liza AJ. 2013. New concepts in liver cirrhosis; clinical significance of sarcopenia in cirrhosis patients. Minerva Gastroenterol Dietol 59: 173-186.

12) Harimoto $N$, Shirabe $K$, Yamashita YI, Ikegami T, Yoshizumi T, Soejima Y, Ikeda T, Maehara Y, Nishie A, Yamanaka T. 2013. Sarcopenia as a predictor of prognosis in patients following hepatectomy for hepatocellular carcinoma. Br J Surg 100: 1523-1530.

13) Miyamoto Y, Baba Y, Sakamoto Y, Ohuchi M, Tokunaga R, Kurashige J, Hiyoshi Y, Iwagami S, Yoshida N, Yoshida M, Watanabe M, Baba H. 2015. Sarcopenia is a negative prognostic factor after curative resection of colorectal cancer. Ann Surg Oncol 22: 2663-2668.

14) Makhija S, Baker J. 2008. The Subjective Global Assessment: a review of its use in clinical practice. Nutr Clin 
Pract 23: 405-409.

15) Bauer JM, Kaiser MJ, Anthony P, Guigoz Y, Sieber CC. 2008. The Mini Nutritional Assessment-its history, today's practice, and future perspectives. Nutr Clin Pract 23: 388-396.

16) Moriwaki H, Aoyagi S, Ishizuka Y, Sasaki M, Santou K, Sugiyama M. 2002. Japanese Anthropometric Reference Data 2001 (JARD2001). Medical Review, Osaka.

17) Mitsiopoulos N, Baumgartner RN, Heymsfield SB, Lyons W, Gallagher D, Ross R. 1998. Cadaver validation of skeletal muscle measurement by magnetic resonance imaging and computerized tomography. J Appl Physiol 85: 115-122.

18) Kvist H, Sjostrom L, Tylen U. 1986. Adipose tissue volume determinations in women by computed tomography: technical considerations. Int J Obes 10: 53-67.

19) Vehmas T, Kairemo KJ, Taavitsainen MJ. 1996. Measuring visceral adipose tissue content from contrast enhanced computed tomography. Int J Obes Relat Metab Disord 20: 570-573.

20) Mourtzakis M, Prado CM, Lieffers JR, Reiman T, McCargar LJ, Baracos VE. 2008. A practical and precise approach to quantification of body composition in cancer patients using computed tomography images acquired during routine care. Appl Physiol Nutr Metab 33: 997-1006.

21) Prado CM, Lieffers JR, McCargar LJ, Reiman T, Sawyer MB, Martin L, Baracos VE. 2008. Prevalence and clinical implications of sarcopenia obesity in patients with solid tumours of the respiratory and gastrointestinal tracts: a population-based study. Lancet Oncol 9: 629-635.

22) Yamada M, Nishiguchi S, Fukutani N, Tanigawa T, Yukutake T, Kayama H, Aoyama T, Arai H. 2013. Prevalence of sarcopenia in community-dwelling Japanese older adults. J Am Med Dir Assoc 14: 911-915.

23) Wakahara T, Shiraki M, Murase K, Fukushima H, Matsuura K, Fukao A, Kinoshita S, Kaifuku N, Arakawa N, Tamura T, Iwasa J, Murakami N, Deguchi T, Moriwaki H. 2007. Nutritional screening with Subjective Global Assessment predicts hospital stay in patients with digestive disease. Nutrition 23: 634-639.

24) Gariballa S, Alessa A. 2013. Sarcopenia: Prevalence and prognostic significance in hospitalized patients. Clin Nutr 32: 772-776.

25) Imai K, Takai K, Hanai T, Ideta T, Miyazaki T, Kochi T, Suetsugu A, Shiraki M, Shimizu M. 2015. Skeletal muscle depletion predicts the prognosis of patients with hepatocellular carcinoma treated with sorafenib. Int $J$ Mol Sci 16: 9612-9624.
26) Iritani S, Imai K, Takai K, Hanai T, Ideta T, Miyazaki T, Suetsugu A, Shiraki M, Shimizu M, Moriwaki H. 2015. Skeletal muscle depletion is an independent prognostic factor for hepatocellular carcinoma. J Gastroenterol 50: 323-332.

27) Hanai T, Shiraki M, Ohnishi S, Miyazaki T, Ideta T, Kochi T, Imai K, Suetsugu A, Takai K, Moriwaki H, Shimizu M. 2016. Rapid skeletal muscle wasting predicts worse survival in patients with liver cirrhosis. Hepatol Res 46: 743-751.

28) Drummond MJ, Rasmussen BB. 2008. Leucine-enriched nutrients and the regulation of mammalian target of rapamycin signalling and human skeletal muscle protein synthesis. Curr Opin Clin Nutr Metab Care 11: 222-226.

29) Hanai T, Shiraki M, Nishimura K, Ohnishi S, Imai K, Suetsugu A, Takai K, Shimizu M, Moriwaki H. 2015. Sarcopenia impairs prognosis of patients with liver cirrhosis. Nutrition 31: 193-199.

30) Uojima H, Sakurai S, Hidaka H, Kinbara T, Sung JH, Ichita C, Tokoro S, Masuda S, Sasaki A, Koizumi K, Egashira H, Kako M, Kobayashi S. 2017. Effect of branched-chain amino acid supplements on muscle strength and muscle mass in patients with liver cirrhosis. Eur J Gastroenterol Hepatol 29: 1402-1407.

31) Hanai T, Shiraki M, Watanabe S, Kochi T, Imai K, Suetsugu A, Takai K, Moriwaki H, Shimizu M. 2017. Sarcopenia predicts minimal hepatic encephalopathy in patients with liver cirrhosis. Hepatol Res 47: 1359-1367.

32) Roman E, Torrades MT, Nadal MJ, Cárdenas G, Nieto JC, Vidal S, Bascuñana H, Juárez C, Guarner C, Córdoba J, Soriano G. 2014. Randomized pilot study: effects of an exercise programme and leucine supplementation in patients with cirrhosis. Dig Dis Sci 59: 1966-1975.

33) Chindapasirt J. 2015. Sarcopenia in cancer patients. Asian Pac J Cancer Prev 16: 8075-8077.

34) Chen L-K, Liu L-K, Woo J, Assantachai P, Auyeung TW, Bahyah KS, Chou MY, Chen LY, Hsu PS, Krairit O, Lee JS, Lee WJ, Lee Y, Liang CK, Limpawattana P, Lin CS, Peng LN, Satake S, Suzuki T, Won CW, Wu CH, Wu SN, Zhang T, Zeng P, Akishita M, Arai H. 2014. Sarcopenia in Asia: consensus report of the Asian Working Group for Sarcopenia. J Am Med Dir Assoc 15: 95-101.

35) Nishikawa H, Shiraki M, Hiramatsu A, Moriya K, Hino K, Nishiguchi S. 2016. Japan Society of Hepatology guidelines for sarcopenia in liver disease (1st edition): Recommendation from the working group for creation of sarcopenia assessment criteria. Hepatol Res 46: 951-963. 